Marquette University

e-Publications@Marquette

College of Education Faculty Research and

Publications

Education, College of

$5-2020$

Beyond Knowledge and Skills: Exploring Leadership Motivation as a Critical Construct for Student Leadership Development

Benjamin Correia-Harker

John P. Dugan

Follow this and additional works at: https://epublications.marquette.edu/edu_fac

Part of the Education Commons 


\title{
Beyond Knowledge and Skills: Exploring Leadership Motivation as a Critical Construct for Student Leadership Development
}

\author{
Benjamin P. Correia-Harker John P. Dugan
}

Theorists position leadership capacity, leadership self-efficacy, and leadership motivation as central constructs in the leadership development process (Chan \& Drasgow, 2001; Dugan, 2017). Although researchers have explored distinct connections between psychological constructs of leadership capacity and leadership self-efficacy, less attention has been given to leadership motivation and its collective connection with these constructs. Findings from this scholarship confirm theorized relationships between these pivotal constructs and situate leadership motivation as a critical component of the developmental process for socially responsible leadership.

Educating citizens who can effectively engage in communities and contribute to positive social change has been a longstanding emphasis of higher education institutions and associations (American Council on Education, 1949; Association of American Colleges \& Universities, 2007). In the past few decades, colleges and universities have begun to address this call through explicit interventions focused on leadership development (Komives, 2011). Leadership educators have developed both curricular and cocurricular opportunities for students to learn about and engage in leadership (Dugan, Bohle, et al., 2011). But are leadership educators maximizing student engagement in leadership development?

With leadership capacity, leadership selfefficacy, and leadership motivation recognized as central psychological constructs in the leadership development process (Chan \& Drasgow, 2001; Dugan, 2017; Keating, Rosch, $\&$ Burgoon, 2014), leadership educators have the opportunity to leverage these constructs for greater impact on leadership development. Whereas students may have particular leadership skill sets and recognize that they can successfully employ those skills, they may not necessarily apply their leadership abilities when encountering social concerns unless they have the drive to do so. To adequately prepare educated citizens who actively address social concerns in their communities, collegiate educators must do more than simply equip students with leadership knowledge and skills: they must also attend to student mindsets that can inhibit or catalyze action for social change.

Although college student leadership development scholars have conducted empirical research related to leadership capacity and leadership self-efficacy (Boatwright \& Egidio, 2003; Dugan, Fath, Howes, Lavelle, \& Polanin, 2013; Dugan, Garland, Jacoby, \& Gasiorski, 2008; Dugan, Kodama, Correia, \& Associates, 2013; Dugan \& Komives, 2007, 2010; Dugan, Kusel, \& Simounet, 2012; Kodama \& Dugan, 2013; McCormick, Tanguma, \& Lopez-Forment, 2002), leadership motivation has received limited recognition in empirical research into college student leadership development (Cho, Harrist, Steele, \& Murn, 2015; Keating et al., 2014; Rosch, Collier, \& Thompson, 2015). With this dearth of scholarship on

Benjamin P. Correia-Harker is Associate Director of Engineering and Innovation Leadership Development at Marquette University. John P. Dugan is Executive Director of Youth Leadership Programs at The Aspen Institute, Washington, DC. 
leadership motivation, researchers have yet to empirically test theoretical relationships between all 3 constructs-leadership capacity, leadership self-efficacy, and leadership motivation-particularly when using the same conceptualization of leadership. Thus, the purpose of this research was to understand the role of leadership motivation in the college student leadership development process as it relates to leadership capacity and leadership self-efficacy.

\section{THEORETICAL MODELS OF LEADERSHIP DEVELOPMENT}

Scholars have made progress in understanding the theoretical and empirical relationships between leadership capacity, self-efficacy, and motivation. Leadership capacity is understood to be the knowledge, skills, and attitudes necessary to engage in leadership (Dugan, $2011 \mathrm{~b}$ ); it is often situated in distinct and specific ways within theoretical models of leadership and many times employs diverse yet sometimes overlapping knowledge, skills, and attitudes across different leadership theories. Connected to but distinct from leadership capacity is leadership self-efficacy, which is the internal belief in one's ability to be successful engaging in the leadership process (Bandura, 1997). Finally, and slightly adapted from Chan and Drasgow's (2001) definition of motivation to lead, leadership motivation is the individual drive that determines the level of intensity and persistence available to engage in the leadership process.

Scholars have theorized three core psychological constructs that are both central to the leadership development process and predictive of leadership behavior (Chan \& Drasgow, 2001; Dugan, 2017); individuals who attend to and foster all three constructs are, theoretically, more likely to participate in leadership development opportunities and, as a result, are more likely to engage in leadership processes. The interplay between the three constructs is believed by some to be mutually reinforcing, with elevated levels in one construct contributing to the increases in the other two (Dugan, 2017); the bidirectional nature of this relationship can result in a recursive, ongoing leadership development process. Contrarily, Chan and Drasgow (2001) hypothesized a more unidirectional model, with leadership self-efficacy influencing leadership motivation, which, in turn, affects leadership capacity. Thus, according to Chan and Drasgow, leadership self-efficacy and leadership motivation are key levers to developing leadership capacity, but gains in capacity do not necessarily result in greater self-efficacy or motivation.

Some leadership studies research has illuminated how leadership self-efficacy predicts leadership motivation (Chan \& Drasgow, 2001; Paglis \& Green, 2002) and leadership capacity (Anderson, Krajewski, Goffin, \& Jackson, 2008; Chemers, Watson, \& May, 2000); leadership scholars have also explored the influence of leadership motivation on various aspects of leadership capacity (Barbuto, 2005; Barbuto, Weltmer, \& Pennisi, 2010; Kark \& Van Dijk, 2007). However, limited college student leadership scholarship exists that empirically connects leadership motivation with leadership selfefficacy and leadership capacity. A few college student leadership studies address leadership motivation as a central construct for leadership development (Cho et al., 2015; Keating et al., 2014; Rosch et al., 2015), yet only one of these studies (Cho et al., 2015) investigated leadership self-efficacy as a predictor of leadership motivation. On the other hand, several college student leadership studies reveal a relationship between leadership self-efficacy and leadership capacity (Dugan, Garland, et al., 2008; Dugan, Kodama, et al., 2013; Dugan \& 
Komives, 2007, 2010). Collectively, leadership studies and college student leadership research seem to support an overarching theoretical connection between leadership capacity, selfefficacy, and motivation.

Three primary issues plague conclusions that can be drawn from research connecting leadership capacity, self-efficacy, and motivation. First, empirical studies have yet to measure the relationship between all three constructs in one study, thus holding constant for these interconnected factors and accounting for potential mediating relationships. Whereas Chan and Drasgow (2001) theorized that leadership motivation mediates the relationship between leadership capacity and leadership self-efficacy, they have yet to empirically test the full model. One can infer relationships by piecing together multiple studies, but measurable relationships have yet to be determined.

The second issue pertains to measurement methods that rely on implicit understandings of leadership. Connotations and assumptions associated with leadership vary greatly (Northouse, 2013); thus, measurement models that default to implicit definitions of leadership leave room for significant doubt as to whether the scale or items measure a consistent construct. And with self-efficacy and motivation being domain-specific-meaning they must be associated with specific tasks or actions (Bandura, 1997)—can a survey accurately capture leadership self-efficacy or motivation without the domain to which they apply being clearly defined? Implicit understandings of leadership pose significant challenges to construct validity, considering that respondents' replies are based on diverse understandings of leadership. When core concepts of a factor scale are left to the discretion of the participants, as is the case with the existing and most frequently employed Motivation to Lead scale (MTL; Chan \&
Drasgow, 2001), the instrument may not capture a consistent psychological construct.

Finally, some scholars have begun to examine the moderating impact that social identities can have on relationships between various factors and psychological constructs of leadership (Dugan, Kodama, et al., 2013; Dugan \& Komives, 2010; Dugan et al., 2012; Kodama \& Dugan, 2013); this scholarship foregrounds a need to continue examining the role of social identities in leadership development. In some cases, findings have indicated that experiences once thought to have a universal influence on leadership development may have no influence or have a negative impact for some social identity groups (Dugan, Kodama, et al., 2013). Leadership literature (Eagly \& Carli, 2007; Fassinger, Shullman, \& Stevenson, 2010; Komives, Dugan, Owen, Slack, Wagner, \& Associates, 2011; Ospina \& Foldy, 2009) and recent empirical studies (Arminio et al., 2000; Boatwright \& Egidio, 2003; Dugan et al., 2012; Kezar \& Moriarty, 2000; Kodama \& Dugan, 2013; Renn \& Bilodeau, 2005; Renn \& Ozaki, 2010) emphasize the importance of attending to various social identities such as race, ethnicity, gender identity, and sexual orientation because leadership practices, interventions, and programs are experienced and/or interpreted differently by students of diverse social identities.

\section{RESEARCH QUESTIONS}

The purpose of this research was to understand the role of leadership motivation in the leadership development process, specifically focusing on how it relates to leadership capacity and leadership self-efficacy. We also intended to gauge how social identities influence leadership motivation's role in the leadership development process. Thus, two questions guided this research: 
1. To what degree and in what ways does leadership motivation relate to leadership capacity and leadership self-efficacy?

2. Are the relationships between leadership capacity, leadership self-efficacy, and leadership motivation moderated by different social identities (e.g., gender, race, or sexual orientation)?

\section{METHOD}

Capitalizing on data from the Multi-Institutional Study of Leadership (MSL), this study consists of a quantitative, secondary analysis of the national data set from 2015 using structural equation modeling (SEM) as the analytic technique.

\section{Research Context and Participants}

The MSL is an international survey designed to understand undergraduate students' experiences with and perceptions of leadership. Administered in Spring 2015, the survey was completed by 98,657 students from 88 four-year colleges and universities. Because the leadership motivation scale was included as part of a subsequent study given to a random selection of the sample, 38,071 cases were considered for this study. Data were examined for missing or potentially manipulated information; cases missing any data or that showed indications of intentional manipulation (see Dugan et al., 2012) were removed, resulting in 38,007 cases included for research analysis. The breakdown of the sample based on race, gender, and sexual orientation was $67.8 \%$ White, 9.8\% Multiracial, 6.6\% Asian American, 6.3\% Latino/Hispanic, 5.2\% African American / Black, 2.6\% unidentified, and less than $1.0 \%$ each for Middle Eastern / Northern African, American Indian / Alaska Native, and Native Hawaiian / Pacific Islander; $63.9 \%$ female, $35.4 \%$ male, and $0.4 \%$ transgender / gender nonconforming; and $91.0 \%$ heterosexual, $3.6 \%$ bisexual, $2.2 \%$ gay/ lesbian, $1.6 \%$ questioning, and $1.0 \%$ queer.

\section{Instrument}

The research design framework for the MSL is adapted from Astin's (1993) inputenvironment-output college impact model. Thus, the instrument is composed of several items and factor scales that measure various input variables, such as demographic information and precollege orientations; environmental variables, such as students' experiences and perceptions of campus; and outcome variables, such as leadership development factors and other psychological constructs. At the heart of the MSL instrument is the socially responsible leadership scale (SRLS), which measures students' perceptions of their knowledge, skills, and attitudes according to the seven values of the social change model of leadership development (Tyree, 1998). With capacity being understood in terms of knowledge, skills, and attitudes (Dugan, 2011b), and using 34 items that were parceled into 6 subscales for this study, the SRLS scale is considered a measure of leadership capacity. Each item employs a 5-point Likert scale to measure degrees of agreement or disagreement. The overarching SRLS scale showed a strong level of reliability with a Cronbach's alpha of .96 for this sample.

Leadership self-efficacy was an exogenous variable for this study as measured by a 4-item scale grounded in Bandura's (1997) work. Items for this scale relate to students' confidence in leading others, organizing a group's tasks to accomplish a goal, taking initiative to improve something, and working with a team on a group project. Respondents were provided with a 4-point Likert-type scale with the following options: 1 (not confident at all), 2 (somewhat confident), 3 (confident), and 4 (very confident). The Leadership Self-Efficacy 
Scale showed a strong level of reliability with a Cronbach's alpha of .87 for the sample.

Although the MTL scale is a commonly used instrument in leadership research (Barbuto, 2005; Chan \& Drasgow, 2001; Keating et al., 2014), in this study, leadership motivation was measured by a 9-item scale based on a motivation metatheory (Leonard, Beauvais, \& Scholl, 1999). The MTL scale has been used in various studies on leadership development, yet, as noted previously, the scale relies on implicit understandings of leadership, and for this study we specifically focused on socially responsible leadership. When considering whether to adapt the MTL scale to this specific form of leadership, we encountered Leonard, Beauvais, and Scholl's (1999) metatheory on motivation. This metatheory is a synthesis of several prior frameworks on motivation, and it places more emphasis on self-concept in relation to motivation than does the MTL. Because of the importance of conceptualization of self in socially responsible leadership (Higher Education Research Institute, 1996), the ways that social identity influences leadership development, and how leadership is a socially constructed process, we created a leadership motivation scale based on this metatheory on motivation.

The metatheory consists of five sources of motivation: intrinsic process, extrinsic/ instrumental motivation, external self-concept, internal self-concept, and goal internalization; however, the MSL instrument only measured three of the five sources due to limited space in the survey and the intended analytic use of leadership motivation as a singular, rather than multifaceted, construct. Research conducted using the Motivation Sources Inventory (MSI), which measures the five sources of motivation, revealed that external self-concept, internal self-concept, and goal internalization were all significantly and positively correlated with each other, yet intrinsic process and extrinsic/ instrumental sources did not have relationships with some of the other sources of motivation (Barbuto, 2005).

Because this research addresses motivation as a single construct, and because the MSI focuses on a work context, we used a leadership motivation scale that included items to measure the interrelated external self-concept, internal self-concept, and goal internalization motivation sources. These three sources of motivation more readily relate to a social change emphasis, while attending to how one's concept of self and association in a group or community play roles in motivation and socially responsible leadership; thus, we designed the items to focus specifically on motivation for socially responsible leadership. Example items include: "I am willing to persist in the face of adversity to meet my group's goals"; "It is important that others think I do high-quality work"; and "I need to see that my actions make a difference in the group." Like the SRLS, students are asked to respond on a 5-point Likert scale from 1 (strongly disagree) to 5 (strongly agree). Leadership motivation exhibits a strong level of reliability with a Cronbach's alpha of .83 for the sample.

\section{Analysis}

This study followed a two-phase process: first, to determine what structural model fit the data best and to review that model; and second, to test for measurement model and path invariance by race, gender, and sexual orientation. To identify a model that best explained the relationships between leadership capacity, leadership self-efficacy, and leadership motivation, we used LISREL (version 8.8for Windows) to conduct comparison tests between three a priori models using SEM. Model 1 (see Figure 1) showed leadership selfefficacy and leadership motivation correlating and both predicting leadership capacity; this closely resembles Dugan's (2017) leadership 


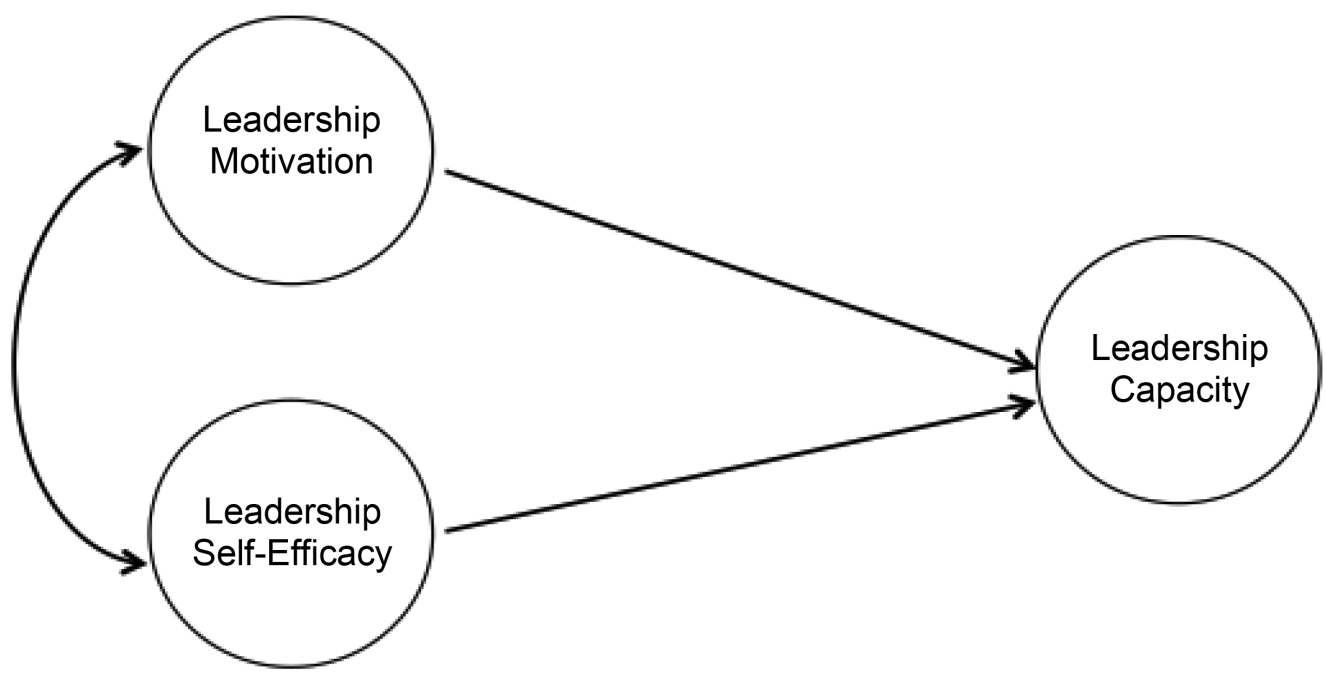

Model 1. Assumes leadership motivation and leadership self-efficacy covary and directly relates to leadership capacity.

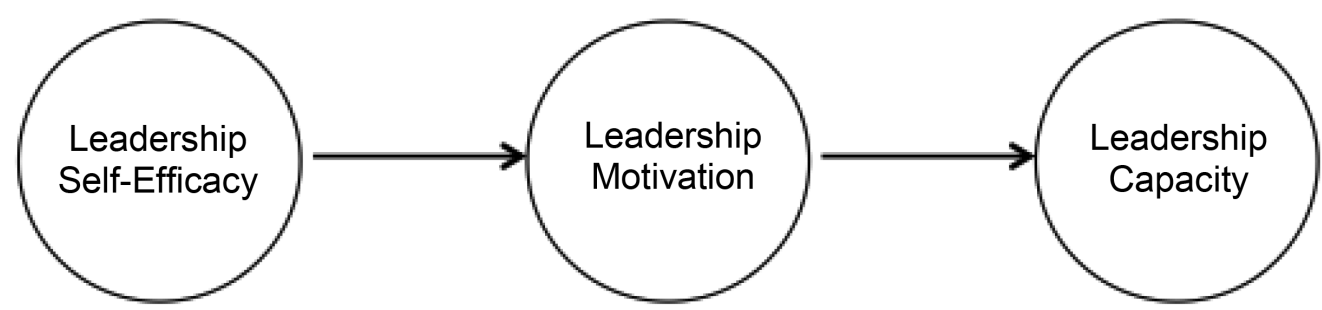

Model 2. Reflects Chan and Drasgow's (2001) model of leadership development.

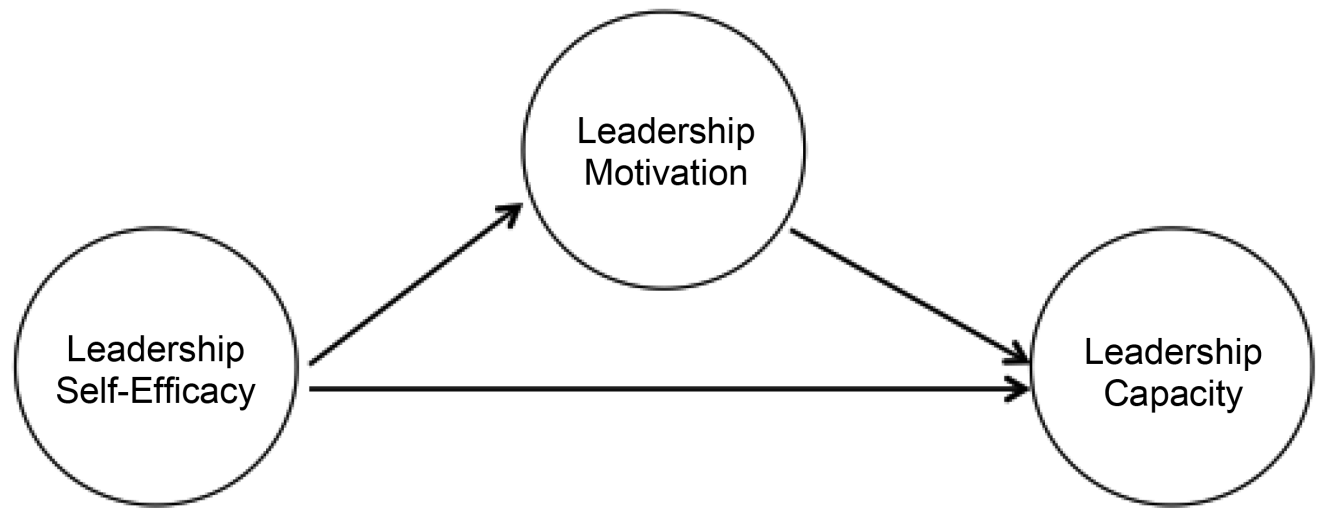

Model 3. Reflects Chan and Drasgow's (2001) model of leadership development with a slight alteration indicating a direct connection between leadership self-efficacy and leadership capacity.

FIGURE 1. Structural Models Compared for Best Fit 
development model. Model 2 showed leadership self-efficacy predicting leadership capacity with leadership motivation completely mediating the relationship; this mirrors Chan and Drasgow's (2001) model of leadership development. Model 3 is the same as Model 2 , except leadership motivation only partially mediated the relationship between leadership self-efficacy and leadership capacity, with a direct path existing between the latter two. Because large samples can produce extreme variations in chi-square values (Maruyama, 1998), the data set was divided randomly into 8 subsets for testing model fit; fit across all 8 data sets was considered to determine a model of best fit. To identify the best-fitting model, we first examined goodness of fit based on four indices (NNFI, CFI, RMSEA, and SRMR); then, if fit was determined to be good for all models, we used the Satorra-Bentler scaled chi-square (Satorra \& Bentler, 2001) to explore whether one model had a better fit to the data than the other two. After determining a bestfitting model, we then ran the model with the entire data set and examined structural paths to ascertain the nature of relationships between psychological constructs.

For the second phase, we used the bestfitting structural model to conduct invariance tests to determine whether measurement and path models held differently for participants of various races, genders, or sexual orientations. We followed Byrne's (1998) recommended series, first testing for configural invariance by assuring that the model adequately fit each group's data well, then testing for measurement invariance by confirming that item factor loadings onto latent constructs and variances of latent constructs were equivalent across groups, and finally verifying structural invariance by testing whether structural paths and endogenous variable residuals varied across groups.

So as not to situate this testing against a referent group, invariance testing was used to examine unique invariance of a particular group when compared to others not of that group (e.g., bisexuals compared to nonbisexuals or women compared to those who are not women). To maintain adequate power and yet include as many social identity groups as possible, we conducting invariance testing on groups with at least 200 participants; thus, invariance testing was conducted for 6 racial groups (African American / Black, Asian / Asian American, Latino, Middle Eastern, multiracial, White), 2 gender groups (women and men), and 6 sexual orientation groups (bisexual, gay/lesbian female, gay male, heterosexual, queer, and questioning). For invariance testing, we pulled a random selection of cases from each social identity to make the size of each social identity subgroup equal and to prevent any one subgroup from being a numerical majority in the aggregated comparison group.

\section{RESULTS}

\section{Model Confirmatory Factor Analyses (CFAs)}

We conducted a two-step modeling process that began with running an oblique CFA for all items and latent factors to be included in the structural model prior to structural model testing (Kline, 2011). The oblique CFA model included 13 observed variables and 6 subscale means that loaded onto the three correlated latent constructs: leadership capacity, leadership self-efficacy, and leadership motivation. For each of the 8 data sets, the structural model CFAs also showed strong fit; NNFI (all .97), CFI (ranging .97 to .98), RMSEA (ranging .066 to .068) and SRMR (ranging .049 to .051) fit indices all fell within good ranges (Browne \& Cudeck, 1993; Hu \& Bentler, 1998; Marsh, Hau, $\&$ Wen, 2004). Thus, the indices from the 
TABLE 1.

Tests of Scaled Chi-Square Difference Between Models 1 \& 3 and 2

\begin{tabular}{|c|c|c|c|c|c|c|c|c|c|c|c|}
\hline $\begin{array}{c}\text { Data } \\
\text { Set }\end{array}$ & Model & $\begin{array}{c}\mathbf{S B}^{\mathbf{a}} \\
\text { Scaled } \chi^{2}\end{array}$ & $d f$ & $\begin{array}{l}\text { Scaling } \\
\text { Factor }\end{array}$ & $\begin{array}{c}\text { SB }^{\text {a Scaled }} \\
\chi^{2} \text { Diff }\end{array}$ & $\Delta d f$ & NNFI & CFI & RMSEA & SRMR & $\mathrm{MNCI}$ \\
\hline 1 & $1 \& 3$ & 3364.35 & 149 & 1.28 & $386.59 *$ & 1 & .971 & .974 & .067 & .049 & 1.020 \\
\hline 1 & 2 & 3743.75 & 150 & 1.28 & & & .967 & .972 & .061 & .067 & 1.022 \\
\hline 2 & $1 \& 3$ & 3338.85 & 149 & 1.34 & $366.94 *$ & 1 & .972 & .976 & .067 & .049 & 1.025 \\
\hline 2 & 2 & 3620.99 & 150 & 1.34 & & & .970 & .974 & .070 & .065 & 1.022 \\
\hline 3 & $1 \& 3$ & 3405.29 & 149 & 1.33 & $338.46 *$ & 1 & .971 & .974 & .068 & .051 & 1.028 \\
\hline 3 & 2 & 3663.71 & 150 & 1.33 & & & .969 & .972 & .070 & .065 & 1.025 \\
\hline 4 & $1 \& 3$ & 3302.33 & 149 & 1.29 & $230.08 *$ & 1 & .971 & .975 & .067 & .049 & 1.019 \\
\hline 4 & 2 & 3564.30 & 150 & 1.29 & & & .969 & .973 & .069 & .063 & 1.019 \\
\hline 5 & $1 \& 3$ & 3293.48 & 149 & 1.29 & $295.61 *$ & 1 & .972 & .975 & .067 & .049 & 1.025 \\
\hline 5 & 2 & 3581.51 & 150 & 1.29 & & & .969 & .973 & .069 & .063 & 1.024 \\
\hline 6 & $1 \& 3$ & 3207.37 & 149 & 1.36 & $299.85^{*}$ & 1 & .972 & .976 & .066 & .049 & 1.022 \\
\hline 6 & 2 & 3504.79 & 150 & 1.36 & & & .970 & .974 & .069 & .064 & 1.020 \\
\hline 7 & $1 \& 3$ & 3381.54 & 149 & 1.33 & $259.06 *$ & 1 & .971 & .975 & .068 & .050 & 1.022 \\
\hline 7 & 2 & 3677.24 & 150 & 1.33 & & & .969 & .973 & .069 & .068 & 1.022 \\
\hline 8 & $1 \& 3$ & 3236.50 & 149 & 1.34 & $235.56 *$ & 1 & .973 & .976 & .066 & .050 & 1.027 \\
\hline 8 & 2 & 3570.44 & 150 & 1.34 & & & .970 & .973 & .069 & .068 & 1.028 \\
\hline
\end{tabular}

a $\mathrm{SB}=$ Satorra-Bentler.

$* p<.001$.

CFAs for the structural model suggest that the observed variables appropriately loaded onto respective latent factors and that those latent factors are correlated. Correlations between each of the factors were significant across all 8 models, with correlations between leadership motivation and leadership self-efficacy ranging from .560 to .591 , leadership motivation and leadership capacity ranging from .681 to .727, and leadership self-efficacy and leadership capacity ranging from .611 to .646 .

\section{Structural Model Testing for Best-Fit Model}

Knowing the CFAs fit well, we then proceeded to the second step and tested the three models outlined earlier to determine which one best reflected the 8 data sets. All three models showed fit indices that fell within recommended ranges indicating strong fit
(Browne \& Cudeck, 1993; Hu \& Bentler, 1998; Marsh et al., 2004). Models 1 and 3 had identical fit indices (Kline, 2011), yet we included both due to conceptual differences. When comparing the equivalent Models 1 and 3 with Model 2, the Satorra-Bentler scaled chisquare difference calculation was statistically significant across all 8 data sets $(p<.001$; Bryant \& Satorra, 2012). Thus, we moved forward with either Model 1 or Model 3.

Because Models 1 and 3 are equivalent in fit and have good levels for a selection of fit indices, they are both equally valid explanations of the relationships between the data. As cross-sectional data, a causal direction of the relationship is not possible to discern. Thus, some would argue that Model 1 is the most appropriate to use moving forward because it does not assume a directional nature between leadership self-efficacy and leadership 
motivation (Cliff, 1983); however, Model 3 reflects a directional relationship between self-efficacy and motivation often discussed in literature, which states that self-efficacy related to a particular task increases one's motivation to engage in that task (Bandura, 1997; Chan \& Drasgow, 2001). Furthermore, SEM output from Model 3 provides additional information to understand direct effects, indirect effects, and possible mediation, which can verify or discount the plausibility of particular theories (Chan \& Drasgow, 2001; Dugan, 2017) Thus, we conducted subsequent analyses using Model 3.

An analysis of the entire data set using Model 3 indicated strong fit (see Table 2). The 4 indices referenced to assess fit, NNFI, CFI, RMSEA, and SRMR, all show strong levels of fit, confirming that the model represents the full data set well. Model 3 and the corresponding standardized values for the unique item error, factor loadings, and path coefficients are displayed in Figure 2. Examining the paths between each of the leadership constructs reveals significant relationships for all paths: leadership self-efficacy to leadership motivation $(\beta=.607, S E=.052, z=16.162, p<.001)$, leadership motivation to leadership capacity $(\beta=.516, S E=.018, z=10.193, p<.001)$, and leadership self-efficacy to leadership capacity $(\beta=.321, S E=.008, z=19.080$, $p<.001)$. When looking at the standardized value for each path coefficient to discern the relative strength of each path, relationships between leadership self-efficacy and leadership motivation, as well as leadership motivation and leadership capacity, seem to be stronger than relationships between leadership selfefficacy and leadership capacity. The exogenous variables explained relatively large portions of the endogenous variable variances. Leadership self-efficacy explains $36.8 \%$ of the variance in leadership motivation, while leadership selfefficacy and leadership motivation explain $57.0 \%$ of the variance in leadership capacity. The variance explained for leadership capacity is larger than what was reported in past research (Dugan \& Komives, 2010); this is mostly likely due to the use of SEM, which parcels out unique error, unlike regression models (Kline, 2011).

Given the structure of Model 3, we could test whether it is possible that leadership motivation mediates the relationship between leadership capacity and leadership self-efficacy. As a potential mediator, leadership motivation would fully or partially explain the relationship between leadership capacity and leadership self-efficacy (Baron \& Kenny, 1986). The Sobel test was used to examine the significance of the unstandardized indirect effect of an exogenous variable on an endogenous variable (Kline, 2011). The indirect effect of leadership self-efficacy on leadership capacity reveals a $z$ score of $16.320(p<.001)$. Because there are significant direct paths between all three factors and a significant indirect effect of leadership self-efficacy on leadership capacity, the relationship of leadership capacity and leadership self-efficacy partially mediated by leadership motivation is a viable reflection of the data.

TABLE 2.

Fit Indices for Model 3 With Full Sample

\begin{tabular}{cccccccc}
\hline & $\begin{array}{c}\text { Satorra-Bentler } \\
\text { Scaled } \chi^{2}\end{array}$ & $d f$ & NNFI & CFI & RMSEA & SRMR & MNCI \\
\hline Model 3 & 14120.8813 & 149 & .987 & .989 & .0497 & .0535 & 1.031 \\
\hline
\end{tabular}




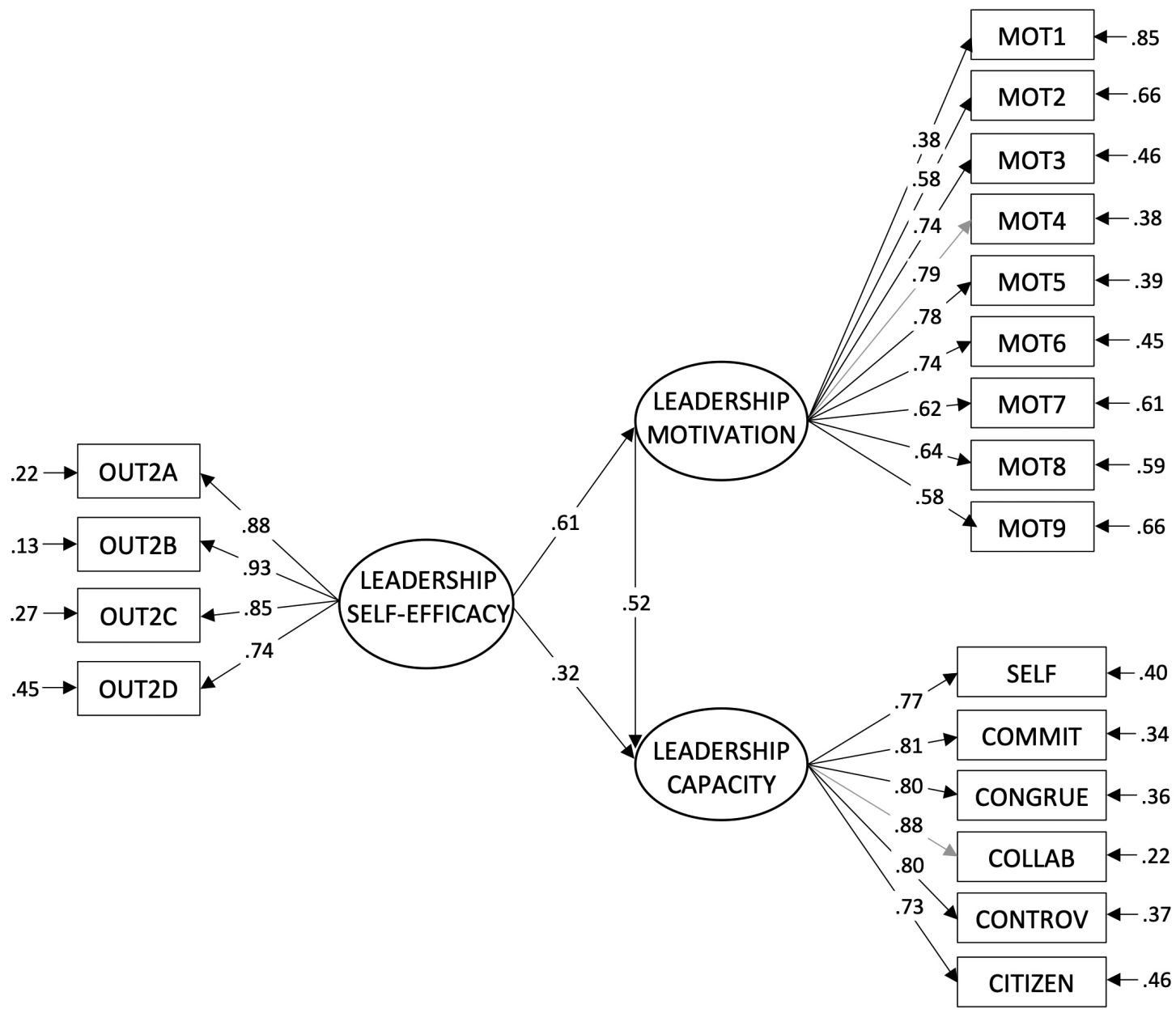

FIGURE 2. Structural Model 3 With Full Sample

\section{Model Invariance by Social Identities}

Testing revealed no variance between participants of any of the social identities and participants who did not identify with those respective social identities. For aspects of invariance testing that required model comparisons, chi-square difference tests are traditionally used (Kline, 2011), but because chi-square difference tests are sensitive to sample size, we scrutinized differences in comparative fit indices and McDonald's noncentrality indices instead (MNCI; Meade, Johnson, \& Braddy, 2008). For all 14 social identity groups tested, results at each step in the testing process revealed no unique invariance of any type.

\section{DISCUSSION}

Model Testing

Models 1 and 3 both had better-fitting indices than Model 2, suggesting that leadership motivation does not completely mediate the relationship between leadership self-efficacy and leadership capacity for this sample. In many explanations of the relationship between leadership capacity and leadership self-efficacy, motivation to learn about and engage in leadership practices is used as an explanation for that connection (Bandura, 1997; Dugan 
\& Komives, 2010; Hannah, Avolio, Luthans, \& Harms, 2008; Paglis, 2010). Results from Model 3 confirm this rationale, positioning leadership motivation as a plausible mediator between leadership capacity and leadership selfefficacy. Larger standardized path coefficients between leadership self-efficacy and leadership motivation, as well as leadership motivation and leadership capacity, suggest this series of relationships is a more robust explanation of the data than the direct relationship between leadership capacity and leadership self-efficacy. However, a unique and significant relationship between leadership capacity and leadership self-efficacy does exist independent of leadership motivation.

Resilience may explain the direct relationships between leadership self-efficacy and leadership motivation. Resilience is understood as both the ability to persist amidst adversity and the ability to employ effective coping mechanisms for stress (Connor \& Davidson, 2003). Although rarely employed in empirical studies of college student leadership development (Kodama, 2014), resilience is theoretically connected to leadership development (Dugan, 2017; Heifetz \& Linsky, 2002), specifically with leadership self-efficacy (Bandura, 1997). Individuals with higher leadership self-efficacy may be more likely to persist in practicing leadership-related tasks, even when they are unsuccessful in initial attempts or encounter others who doubt their leadership ability.

Model testing validated Chan and Drasgow's (2001) conception of leadership development as Model 2 indicated strong fit indices, but other structural models better explained the nature of the relationship between the three central leadership constructs explored in this study. Similar to Dugan's (2017) model, Chan and Drasgow integrated a cyclical process in which leadership self-efficacy influences leadership motivation which then influences leadership capacity; this series of influences culminates with leadership enactment but also cycles back to impact leadership selfefficacy and leadership motivation. Although generally congruent with Chan and Drasgow's theory, this study contradicts their model, which suggests no direct relationship between leadership capacity and leadership self-efficacy. Findings from this research not only show the plausibility of leadership motivation largely mediating the relationship, but also show that a direct and/or other mediated path between leadership capacity and leadership self-efficacy exists. Thus, an additional path between leadership capacity and leadership self-efficacy would make Chan and Drasgow's model better reflect what this empirical work indicates.

This study also highlights the difficulties inherent in discerning directional relationships with cross-sectional data. The equivalent fit of Models 1 and 3 exemplifies the limitations of using cross-sectional data to ascertain causal relationships. This research can confirm directional relationships as reasonable explanations but cannot confirm them as conclusions. Even though Model 3 was used for subsequent analyses due to additional information provided in the output, it is important to note that it is no more valid than Model 1 in terms of explaining the relationships between leadership capacity, leadership self-efficacy, and leadership motivation. This highlights the need for longitudinal studies of leadership development.

\section{Invariance Testing}

Testing for unique invariance based on race, gender, and sexual orientation did not reveal any configural, measurement, or structural variances. Thus, regardless of participants' race, gender, or sexual orientation, students responded to the items in similar patterns, psychological constructs held consistently, and relationships between constructs were relatively similar in direction and strength. These 
findings bolster the psychometric rigor of the MSL to measure socially responsible leadership capacity, self-efficacy, and motivation, further confirming construct validity and reliability across diverse sample groups.

Although measurement and structural path models were found to be invariant across race, gender, and sexual orientation, this does not mean that all factor relationships associated with these outcomes are consistent across these social identities. For example, students of distinct racial, gender, or sexual orientation groups may express different rates of leadership motivation, or particular environmental factors may influence different patterns of growth in leadership motivation for certain groups. Additionally, this research addressed the unique variance of particular groups, comparing students of a particular identity to other respondents not of that identity; thus, leadership construct measures, or relationships between leadership capacity, self-efficacy, and motivation for a certain racial, gender, or sexual orientation identity, may significantly vary from another specific identity within that same group. Even with these cautions, findings from invariance testing point to relatively generalizable relationships between leadership capacity, self-efficacy, and motivation, calling on researchers and practitioners to establish scholarly work and effective interventions that can leverage greater leadership development for all students.

\section{LIMITATIONS}

There are some study limitations that influence the ways this research should be interpreted and applied. First, we used a cross-sectional survey; thus, relationships identified were not causal in nature. Model 3 supports the viability of some theoretical relationships between the three constructs, but the direction of those relationships cannot be confirmed in this study. Nevertheless, this study reveals insights into whether relationships between constructs exist and, if so, how those relationships held consistently based on social identities.

Second, we also employed a motivational leadership scale that is partially representative of the metatheory from which it was derived. Based on Barbuto's (2005) research, including only the internal self-concept, external selfconcept, and goal internalization allowed for a stronger single measure of motivation for this study. And yet exclusion of two sources of motivation constricted the complexity of the theorized construct in this research; inclusion of intrinsic process and extrinsic/ instrumental sources in future research where motivation is employed as a multifaceted factor will only deepen awareness of how leadership motivation sources influence socially responsible leadership.

Third, we used social identity categories to capture the influences of identities, which are complex and fluid self-constructs. Even though reductionist racial categories were used, disaggregating by demographic groups provided a layer of critical analysis that set a base-level understanding of the relationships between central leadership psychological constructs as related to social identities. Furthermore, this study only included three social identities (race, gender, and sexual orientation), whereas variance might exist across others such as nationality and religious identity. With resounding calls from researchers to disaggregate data (Dugan, Kodama, et al., 2013; Kodama \& Dugan, 2013), this was a strong first step toward understanding diverse college students' leadership development.

\section{IMPLICATIONS FOR RESEARCH}

One of the most striking implications is the need for research into leadership motivation in college student leadership development. 
Leadership motivation has received marginal attention at best in the college student leadership development literature, and even that attention is based on a measurement that relies on implicit understandings of leadership (Cho et al., 2015; Keating et al., 2014; Rosch et al., 2015). Leadership motivation has clear connections to leadership capacity and leadership self-efficacy in the leadership development process, showing an even stronger relationship with each of these latter constructs than they have with each other. Just as leadership self-efficacy has been included as an intermediary factor in college student leadership development studies (Dugan \& Komives, 2010), leadership motivation also needs to be included in analyses to gain a more complete picture of the role it plays in leadership development.

To date, all empirical studies in college student leadership development literature have used Chan and Drasgow's (2001) MTL scales (Cho et al., 2015; Keating et al., 2014; Rosch et al., 2015). Self-efficacy and motivation are domain-specific psychological constructs, meaning they must be associated with particular tasks or actions (Bandura, 1997); Chan and Drasgow's MTL scale relies on the respondents' implicit understanding of leadership, without any assurance that it accurately captures a salient understanding of leadership motivation. With a wealth of empirical research related to college student leadership development based on the SCM (Campbell, Smith, Dugan, \& Komives, 2012; Dugan, Fath, et al., 2013; Dugan, Kodama, et al., 2013; Dugan \& Komives, 2010; Dugan \& Yurman, 2011; Johnson, 2015; Kodama, 2014; Kodama \& Dugan, 2013), relying on the current college student leadership motivation literature might be problematic when considering its relation to socially responsible leadership. Additionally, because social location plays an influential role in shaping how leaders are perceived and how leadership is enacted (Eagly \& Carli, 2007; Fassinger et al., 2010; Ospina \& Foldy, 2009), the MTL scales may be susceptible to variance by different social identities. Researchers not only need to include leadership motivation in more empirical research, but they also need to carefully consider what measurements of leadership motivation are used.

Because leadership is a socially constructed phenomenon and is connoted in a number of ways (Dugan, 2017; Eagly \& Carli, 2007; Fassinger et al., 2010; Northouse, 2013; Ospina \& Foldy, 2011; Sanchez-Hucles \& Davis, 2010), leadership research that addresses relationships between leadership constructs requires scales that are grounded in consistent theoretical frameworks. The leadership motivation scales used in this research hold well and consistently across social identity groups; additionally, they were created with the domain of socially responsible leadership in mind. Using leadership measurement scales that align via underlying theoretical foundations is critical to clearly interpret findings in both scholarly and practical settings.

\section{IMPLICATIONS FOR PRACTICE}

With leadership motivation being empirically confirmed as a critical component of the college student leadership development process, leadership educators need to integrate specific educational experiences and interventions aimed at boosting leadership motivation and leveraging its influence on leadership development. Often, educators focus on leadership capacity, teaching different skills, concepts, or theories for students to implement in their various roles and contexts (Dugan, 2011a; Dugan, Rossetti Morosini, \& Beazley, 2011; Dugan, Turman, \& Torrez, 2015). As leadership studies scholars began 
to theorize about leadership self-efficacy's role in the leadership development process, and as subsequent research emerged (Chan \& Drasgow, 2001; Hannah et al., 2008), college educators began to explore how leadership self-efficacy could be leveraged for greater student leadership development (Dugan, Garland, et al., 2008; Dugan, Kodama, et al., 2013; Dugan \& Komives, 2010; Kodama \& Dugan, 2013). Leadership self-efficacy is sometimes explained in terms of motivation: as students feel more confident in their leadership abilities, they will tend to engage in leadership development and leadership opportunities more often (Bandura, 1997; Chan \& Drasgow, 2001; Dugan \& Komives, 2010). Whereas leadership self-efficacy can be used as an effective lever for leadership motivation, there are other considerations practitioners can capitalize on to maximize leadership motivation in the leadership development process. The three components of leadership motivation included in this studyexternal self-concept, internal self-concept, and goal internalization-can provide insight into ways of fostering leadership motivation.

Motivation attributed to external selfconcept relates to an individual's drive as sparked by others' perceptions (Leonard et al., 1999); others' positive or negative perceptions, whether directly related to an individual or by association with a group, can catalyze an individual to take action, whether that action is to counteract those perceptions or confirm them. Individuals generally want others to see them in a positive light, so they will often act in a way that strengthens that positive perception (Ridgeway, 2003). As students receive mixed messages about their perceived access or capability to engage in leadership processes, mentors, staff, faculty, and peers can play powerful roles in contributing messages that reinforce student engagement in leadership development (Howes, 2016).
Educators and mentors can also help students reframe external perceptions so they are not internalized and result in disengagement but instead are considered in ways that instigate growth and action.

Motivation related to internal self-concept focuses on behavior that is driven by how individuals perceive their best self should be or act (Bandura, 1997; Leonard et al., 1999). Based on how they understand leadership, students may see leadership mindsets, behaviors, and skill sets as part of this idealized self. However, because of dominant narratives around leadership, some students do not see themselves as capable of engaging in leadership, or they do not want to be associated with it (Arminio et al., 2000; Dugan, 2017; Eagly \& Carli, 2007; Howes, 2016). As a result, many students may self-select out of leadership development opportunities because their concept of leadership does not align with who they think they are or should be. Thus, leadership educators have a responsibility to present critical frameworks that open space for all students to see themselves engaging in the leadership process. As students are able to see ways in which they all contribute to the leadership process, they can then internalize concepts of self that engage in leadership and seek out leadership development opportunities that help them work toward that idealized self.

Goal internalization pertains to motivation gained or diminished by personal commitment to a group or community's desired outcome (Leonard et al., 1999). Students may have strong commitments to social issues that, even if rectified, do not directly benefit themselves. Leadership educators can capitalize on this passion for a cause to encourage students to engage in the leadership process. When students are helped to understand how their engagement in the leadership process can help them make progress toward a goal, they may be more motivated to participate in 
leadership development experiences, regardless of what others think or whether they perceive themselves as leaders.

\section{FUTURE RESEARCH}

This study helps to answer key questions for college student leadership development scholars, yet more research is needed to understand how and why socially responsible leadership motivation levels vary for students of different social identities. Studies on leadership capacity and leadership self-efficacy have delved into these differences, finding varying levels of these constructs in students of different social identities (Dugan, Kodama, et al., 2013; Dugan \& Komives, 2007, 2010; Dugan, Komives, \& Segar, 2008; Dugan \& Yurman, 2011). Similarly, additional research is needed to explore to what degree diverse groups report different levels of leadership motivation and what might account for such differences. Researchers also need to explore what precollege and environmental factors relate to leadership motivation. On average, students have at least 18 years of living in particular social contexts and engaging in certain communities; thus, just as they influence other leadership development factors, precollege factors could play meaningful roles in differentiating students' motivations to engage in leadership development and the leadership process (Dugan $\&$ Komives, 2010). Building upon precollege factors, what collegiate experiences appear to influence leadership motivation, and how do social identities influence the impact of these experiences? Participation in a number of collegiate activities correlates with students' leadership capacities (Antonio, 2001; Dugan, Bohle, et al., 2011; Dugan, Garland, et al., 2008; Dugan, Kodama, et al., 2013; Dugan \& Komives, 2010; Kezar \& Moriarty, 2000; Zimmerman-Oster \& Burkhardt, 1999) and leadership self-efficacy (Dugan, Fath, et al., 2013; Dugan, Garland, et al., 2008; Kodama \& Dugan, 2013). It stands to reason that similar patterns may exist between certain collegiate experiences and leadership motivation as well.

Researchers can also turn their attention to studies that include other psychological constructs that theoretically connect to the leadership development process, such as cognitive and metacognitive ability, systemic thinking, resilience, other forms of self-efficacy (e.g., learning, resilient), critical reflection, and social perspective taking (Chan \& Drasgow, 2001; Dugan, 2017; Dugan, Kodama, et al., 2013; Hannah et al., 2008; Machida \& Schaubroeck, 2011; Marshall-Meis, Fleishman, Martin, Zaccaro, Baughman, \& McGee, 2000; Preskill \& Brookfield, 2009; Thompson, 2006). Studies with other psychological constructs may provide a more nuanced understanding of the relationships between leadership capacity, leadership self-efficacy, and leadership motivation. Finally, longitudinal research on leadership development is needed to truly understand how the leadership development process unfolds during college and how collegiate experiences impact leadership development. Understanding the sequence of how the relationships between leadership capacity, leadership self-efficacy, and leadership motivation unfold over time will provide invaluable information to leadership educators.

\section{CONCLUSION}

This research sheds light on the important role leadership motivation plays in leadership development, specifically as it relates to leadership capacity and leadership self-efficacy. The relationships between constructs hold consistently across all groups tested; this elevates the importance of this central set of constructs in the leadership development 
process and provides an impetus for leadership educators to meaningfully integrate experiences that tap into all three levers to promote the greatest development for the broadest set of individuals. Essentially, leadership motivation is a critical component of all students' leadership development; leadership educators must attend to leadership motivation if higher education intends to maximize its impact on students' leadership development.

Correspondence concerning this article should be addressed to Benjamin P. Correia-Harker at ben.correiaharker@marquette.edu

\section{REFERENCES}

American Council on Education. (1949). The student personnel point of view. Washington, DC: Author.

Anderson, D. W., Krajewski, H. T., Goffin, R. D., \& Jackson, D. N. (2008). A leadership self-efficacy taxonomy and its relation to effective leadership. Leadership Quarterly, 19, 595-608.

Antonio, A. L. (2001). The role of interracial interaction in the development of leadership skills and cultural knowledge and understanding. Research in Higher Education, 42, 593-617.

Arminio, J. L., Carter, S., Jones, S. E., Kruger, K., Lucas, N., Washington, J., Young, N., \& Scott, A. (2000). Leadership experiences of Students of Color. NASPA Journal, 37, 496-510.

Association of American Colleges \& Universities. (2007). College learning for the new global century. Washington, DC: Author.

Astin, A. W. (1993). What matters in college? Four critical years revisited. San Francisco, CA: Jossey-Bass.

Bandura, A. (1997). Self-efficacy: The exercise of control. New York, NY: W. H. Freeman.

Barbuto, J. E., Jr. (2005). Motivation and transactional, charismatic, and transformational leadership: A test of antecedents. Journal of Leadership and Organizational Studies, 11(4), 26-40.

Barbuto, J. E., Jr., Weltmer, D. F., \& Pennisi, L. A. (2010). Locus of control, sources of motivation, and mental boundaries as antecedents of leader-member exchange quality. Psychological Reports, 106, 175-188.

Baron, R. M., \& Kenny, D. A. (1986). The moderatormediator variable distinction in social psychological research: Conceptual, strategic, and statistical considerations. Journal of Personality and Social Psychology, 51, 1173-1182.

Boatwright, K. J., \& Egidio, R. K. (2003). Psychological predictors of college women's leadership aspirations. Journal of College Student Development, 44, 653-669.

Browne, M. W., \& Cudeck, R. (1993). Alternative ways of assessing model fit. In K. A. Bollen \& J. S. Long (Eds.), Testing structural equation models (pp. 136-162). Newbury Park, CA: SAGE.

Bryant, F. B., \& Satorra, A. (2012). Principles and practice of scaled difference chi-square testing. Structural Equation Modeling, 19, 372-398.

Byrne, B. M. (1998). Structural equation modeling with LISREL, PRELIS, and SIMPLIS: Basic concepts, applications, and programming. Mahwah, NJ: Lawrence Erlbaum.

Campbell, C. M., Smith, M., Dugan, J. P., \& Komives, S. R. (2012). Mentors and college student leadership outcomes: The importance of position and process. Review of Higher Education, 35, 595-625.

Chan, K., \& Drasgow, F. (2001). Toward a theory of individual differences and leadership: Understanding the motivation to lead. Journal of Applied Psychology, 86, 481-498.

Chemers, M. M., Watson, C. B., \& May, S. T. (2000). Dispositional affect and leadership effectiveness: A comparison of self-esteem, optimism, and efficacy. Personality and Social Psychology Bulletin, 26, 267-277.

Cho, Y., Harrist, S., Steele, M., \& Murn, L. T. (2015). College student motivation to lead in relation to basic psychological need satisfaction and leadership self-efficacy. Journal of College Student Development, 56, 32-44.

Cliff, N. (1983). Some cautions concerning the application of causal modeling methods. Multivariate Behavioral Research, 18, 115-126.

Connor, K. M., \& Davidson, J. R. T. (2003). The development of a new resilience scale: The Connor-Davidson resilience scale (CD-RISC). Depression and Anxiety, 18, 76-82.

Dugan, J. P. (2011a). Pervasive myths in leadership development: Unpacking constraints on leadership learning. Journal of Leadership Studies, 5(2), 79-84.

Dugan, J. P. (2011b). Research on college student leadership development. In S. R. Komives, J. P. Dugan, J. E. Owen, C. Slack, W. Wagner \& Associates (Eds.), The handbook for student leadership development (2nd ed.; pp. 1-32). San Francisco, CA: Jossey-Bass.

Dugan, J. P. (2017). Leadership theory: Cultivating critical perspectives. San Francisco, CA: Jossey-Bass.

Dugan, J. P., Bohle, C. W., Gebhardt, M., Hofert, M., Wilk, E., \& Cooney, M. A. (2011). Influences of leadership program participation on students' capacities for socially responsible leadership. Journal of Student Affairs Research and Practice, 48, 65-84.

Dugan, J. P., Fath, K. Q., Howes, S. D., Lavelle, K. R., \& Polanin, J. R. (2013). Developing the leadership capacity and leader efficacy of college women in science, technology, engineering, and math fields. Journal of Leadership Studies, 7(3), 6-23.

Dugan, J. P., Garland, J. L., Jacoby, B., \& Gasiorski, A. (2008). Understanding commuter student self-efficacy for leadership: A within-group analysis. NASPA Journal, 45, 282-310.

Dugan, J. P., Kodama, C. M., Correia, B., \& Associates. (2013). Multi-Institutional Study of Leadership insight report: Leadership program delivery. College Park, MD: National Clearinghouse for Leadership Programs.

Dugan, J. P., \& Komives, S. R. (2007). Developing leadership capacity in college students: Findings from a national study. A report from the Multi-Institutional Study of Leadership. College Park, MD: National Clearinghouse for Leadership Programs. 
Dugan, J. P., \& Komives, S. R. (2010). Influences on college students' capacity for socially responsible leadership. Journal of College Student Development, 51, 525-549.

Dugan, J. P., Komives, S. R., \& Segar, T. C. (2008). College student capacity for socially responsible leadership: Understanding norms and influences of race, gender, and sexual orientation. NASPA Journal, 45, 475-500.

Dugan, J. P., Kusel, M. L., \& Simounet, D. M. (2012). Transgender college students: An exploratory study of perceptions, engagement, and educational outcomes. Journal of College Student Development, 53, 719-736.

Dugan, J. P., Rossetti Morosini, A. M., \& Beazley, M. R. (2011). Cultural transferability of socially responsible leadership: Findings from the United States and Mexico. Journal of College Student Development, 52, 456-474.

Dugan, J. P., Turman, N. T., \& Torrez, M. A. (2015). When recreation is more than just sport: Advancing the leadership development of students in intramurals and club sports. Recreational Sports Journal, 39, 37-48.

Dugan, J. P., \& Yurman, L. (2011). Commonalities and differences among lesbian, gay, and bisexual college students: Considerations for research and practice. Journal of College Student Development, 52, 201-216.

Eagly, A. H., \& Carli, L. L. (2007). Through the labyrinth: The truth about how women become leaders. Boston, MA: Harvard Business School Press.

Fassinger, R. E., Shullman, S. L., \& Stevenson, M. R. (2010). Toward an affirmative lesbian, gay, bisexual, and transgender leadership paradigm. American Psychologist, 65, 216-224.

Hannah, S. T., Avolio, B. J., Luthans, F., \& Harms, P. D. (2008). Leadership efficacy: Review and future directions. Leadership Quarterly, 19, 669-692.

Heifetz, R. A., \& Linsky, M. (2002). Leadership on the line: Staying alive through the dangers of leading. Boston, MA: Harvard Business School Press.

Higher Education Research Institute. (1996). A social change model of leadership development: Guidebook version 3. Los Angeles: HERI, University of California. Retrieved from http://www.heri.ucla.edu/PDFs/pubs/ASocialChangeModel ofLeadershipDevelopment.pdf

Howes, S. D. (2016). "You're kind of just conditioned": Women and female college students' defiance of dominant social messages in the development of leader self-efficacy (Unpublished doctoral dissertation). Loyola University Chicago, Chicago, IL.

Hu, L., \& Bentler, P. M. (1998). Fit indices in covariance structure modeling: Sensitivity to underparameterized model misspecification. Psychological Methods, 3, 424-453.

Johnson, M. R. (2015). Developing college students' civic identity: The role of social perspective taking and sociocultural issues discussions. Journal of College Student Development, 56, 687-704. doi:10.1353/csd.2015.0074

Kark, R., \& Van Dijk, D. (2007). Motivation to lead, motivation to follow: The role of self-regulatory focus in leadership process. Academy of Management Review, 32, 500-528.

Keating, K., Rosch, D., \& Burgoon, L. (2014). Developmental readiness for leadership: The differential effects of leadership courses on creating "ready, willing, and able" leaders. Journal of Leadership Education, 13, 1-16. doi:1012806/V13/I3/R1
Kezar, A., \& Moriarty, D. (2000). Expanding our understanding of student leadership development: A study exploring gender and ethnic identity. Journal of College Student Development, 41, 55-68.

Kline, R. B. (2011). Principles and practice of structural equation modeling (3rd ed.). New York, NY: Guilford.

Kodama, C. M. (2014). A structural model of leadership selfefficacy for Asian American students: Examining influences of collective racial esteem and resilience (Doctoral dissertation). Retrieved from Theses and Dissertation at Loyola eCommons. (Paper 1095)

Kodama, C. M., \& Dugan, J. P. (2013). Leveraging leadership efficacy for college students: Disaggregating data to examine unique predictors by race. Equity \& Excellence in Education, 46, 184-201.

Komives, S. R. (2011). Advancing leadership education. In S. R. Komives, J. P. Dugan, J. E. Owen, C. Slack, W. Wagner \& Associates (Eds.), The handbook for student leadership development (2nd ed.; pp. 1-32). San Francisco, CA: Jossey-Bass.

Komives, S. R., Dugan, J. P., Owen, J. E., Slack, C., Wagner, W., \& Associates, (Eds.). (2011). The handbook for student leadership development (2nd ed.). San Francisco, CA: Jossey-Bass.

Leonard, N. H., Beauvais, L. L., \& Scholl, R. W. (1999). Work motivation: The incorporation of self-concept-based processes. Human Relations, 52, 969-998.

Machida, M., \& Schaubroeck, J. (2011). The role of selfefficacy beliefs in leader development. Journal of Leadership \& Organizational Studies, 18, 459-468.

Marsh, H. W., Hau, K. T., \& Wen, Z. (2004). In search of golden rules: Comment on hypothesis-testing approaches to setting cutoff values for fit indexes and dangers in overgeneralizing Hu and Bentler's (1999) findings. Structural Equation Modeling, 11, 320-341.

Marshall-Meis, J. C., Fleishman, E. A., Martin, J. A., Zaccaro, S. J., Baughman, W. A., \& McGee, M. L. (2000). Development and evaluation of cognitive and metacognitive measures for predicting leadership potential. Leadership Quarterly, 11, 135-153.

Maruyama, G. M. (1998). Basics of structural equation modeling. Thousand Oaks, CA: SAGE.

McCormick, M. J., Tanguma, J., \& Lopez-Forment, A. S. (2002). Extending self-efficacy theory to leadership: A review and empirical test. Journal of Leadership Education, 1, 1-15.

Meade, A. W., Johnson, E. C., \& Braddy, P. W. (2008). Power and sensitivity of alternative fit indices in tests of measurement invariance. Journal of Applied Psychology, 93, 568-592.

Northouse, P. G. (2013). Leadership: Theory and practice (6th ed.). Thousand Oaks, CA: SAGE.

Ospina, S., \& Foldy, E. (2009). A critical review of race and ethnicity in the leadership literature: Surfacing context, power and the collective dimensions of leadership. Leadership Quarterly, 20, 876-896.

Paglis, L. L. (2010). Leadership self-efficacy: Research findings and practical applications. Journal of Management Development, 29, 771-782.

Paglis, L. L., \& Green, S. G. (2002). Leadership self-efficacy and managers' motivation for leading change. Journal of Organizational Behavior, 23, 215-235. 
Preskill, S., \& Brookfield, S. D. (2009). Learning as a way of leading: Lessons from the struggle for social justice. San Francisco, CA: Jossey-Bass.

Renn, K. A., \& Bilodeau, B. L. (2005). Leadership identity development among lesbian, gay, bisexual, and transgender student leaders. NASPA Journal, 42, 342-367.

Renn, K. A., \& Ozaki, C. C. (2010). Psychosocial and leadership identities among leaders of identity-based organizations. Journal of Diversity in Higher Education, 3, 14-26.

Ridgeway, C. L. (2003). Social status and group structure. In M. A. Hogg \& S. Tindale (Eds.), Blackwell handbook of social psychology: Group processes (pp. 352-375). Malden, MA: Blackwell.

Rosch, D. M., Collier, D., \& Thompson, S. E. (2015). An exploration of students' motivation to lead: An analysis by race, gender, and student leadership behaviors. Journal of College Student Development, 56, 286-291.
Sanchez-Hucles, J. V., \& Davis, D. D. (2010). Women and Women of Color in leadership: Complexity, identity, and intersectionality. American Psychologist, 65, 171-181.

Satorra, A., \& Bentler, P. M. (2001). A scaled difference chi-square test statistic for moment structure analysis. Psychometrika, 66, 507-514.

Thompson, M. D. (2006). Student leadership process development: An assessment of contributing college resources. Journal of College Student Development, 47, 343-350.

Tyree, T. M. (1998). Designing an instrument to measure socially responsible leadership using the social change model of leadership development. Dissertation Abstracts International, 59(06), 1945. (AAT 9836493)

Zimmerman-Oster, K., \& Burkhardt, J. (1999). Leadership in the making: Impact and insights from leadership development programs in U.S. colleges and universities. Battle Creek, MI: W. K. Kellogg Foundation. 